\title{
Measurement of the anticipatory goal response in instrumental runway conditioning
}

\author{
Edward B. Deaux, THE UNIVERSTYY OF TEXAS \\ Riehard L. Patten, I STATE UNIVERSTY OF IOWA
}

\begin{abstract}
Abstraet
Seven rats were run to water reinforcement in a straight runway while a measure was taken of anticipatory licking in the runway and consummatory licking in the goal box. Licking rate was shown to increase in a positively accelerated manner as $\mathrm{S}$ approached the goal box and to increase in a negatively accelerated manner with training. The results are discussed in relation to Spence's $r_{g^{-s}}$ mechanism.

\section{Problem}

In the learning theories of Hull (1931) and Spence (1951, 1956), the $\mathrm{r}_{\mathrm{g}^{-\mathrm{s}}} \mathrm{g}$ mechanism plays a large role in the explanation of appetitional instrumental conditioning. In the runway situation, stimulation by cues at the beginning of the alley are assumed to evoke such components of the consummatory response as can occur without the actual presence of the goal object. The interoceptive cues produced by this classical conditioned response in turn are assumed to become conditioned to the instrumental locomotor response and thus become a determiner of its excitatory strength (Spence, 1951, 1956). Development of a technique by which licking can be recorded from a moving rat has made it possible to measure anticipatory goal responses in the runway and thus to test these assumptions. This paper is a report of the research conducted with this technique.

\section{Method}

Figure 1 shows the device used to detect the licking responses and present the water to the rat in the goal box. A small elastic harness held a bit made of $1 / 16$-in brass tubing which fit in the S's mouth and held the headset in place. Fastened to the headset was a piece of

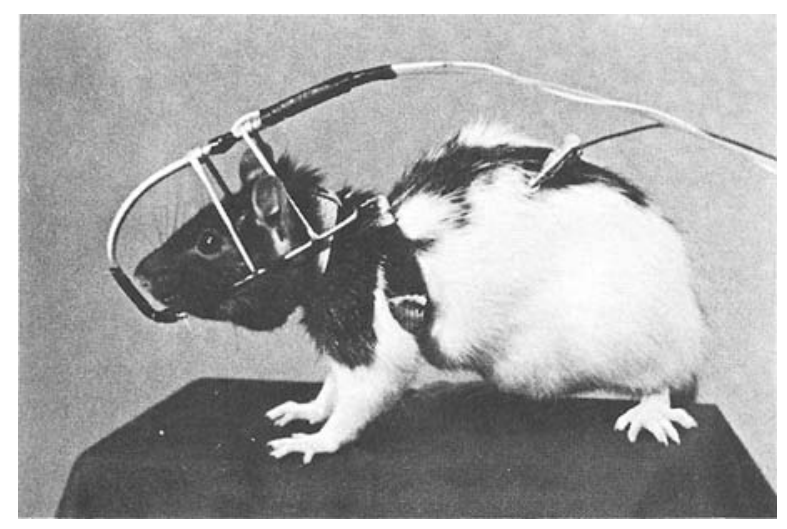

Fig. 1. Illustration of the technique used for detecting licking responses.
$3 / 32-$ in aluminum tubing to which a wire from the contact side of a Hunter contact relay was connected. A grounding electrode was implanted sub-dermally on S's back, and with each contact with the aluminum tube a circuit was made through the animal. A Brush penmotor was used to give a graphic record of the licking rate in each foot of the runway and in the goal box where water was fed through the aluminum tube for $8 \mathrm{sec} .(.20 \mathrm{ml})$. The unit allowed complete mobility without any variation in the distance from the tubing to S's mouth and consequently with no variation in the accuracy of the licking count.

The straight runway employed was $5 \mathrm{ft} 1$ in long, 11 in high, and $23 / 4$ in wide and was painted flat black. The end wall of the goal box was illuminated by a 15-w bulb behind a sheet of Plexiglas, also painted black. Time measures were taken from the opening of the start box door to the end of the first foot, from the first to the second foot, and for each following foot down to 1 in from the end wall of the goal box, at which point the water was presented.

The Ss were seven naive female hooded rats, approximately 130 days of age, and were deprived of water for $22 \mathrm{hr}$. before each session. Each was adapted to the harness and headset for two 15-min. sessions prior to

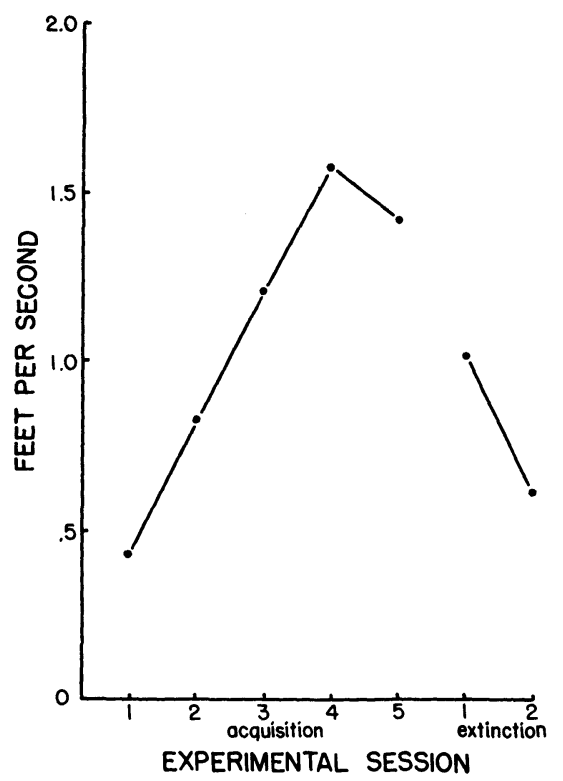

Fig. 2. Running speed in the second foot of the runway for each seven-trial session. 


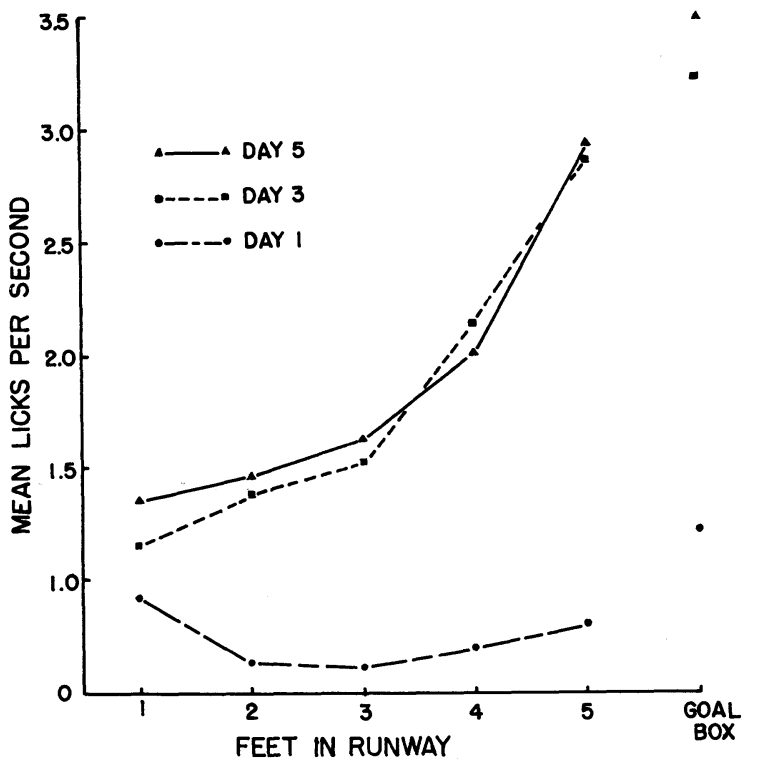

Fig. 3. Rate of licking in each foot of the runway and in the goal box.

the start of training. During both acquisition and extinction phases Ss were given seven trials a day with an intertrial interval of $15 \mathrm{~min}$.

\section{Results}

Running speed in the second foot of the runway for each of the seven 7-trial sessions is shown in Fig. 2 and gives an indication of the strength of the instrumental locomotor response. Figure 3 presents the anticipatory goal response data for the first, third, and fifth acquisition sessions. It can be seen that the slope of the licking gradient increases greatly from Day 1 to Day 3 and that there is little change from Day 3 to Day 5 . The licking rate in the goal box increases accordingly to a mean of 3.02 licks per second for the fifth session.

In the first extinction session there was a significant decrease in the licking rate in the alley $(F, 35.20$; df, $1 / 12 ; p<.05)$, and the goal box licking rate dropped to 1.07 licks per second. On the second day of extinction the gradient of licking in the alley was essentially flat, and the goal box rate decreased further to .48 licks per second.

\section{Diseussion}

The results indicate that anticipatory licking increases in the runway as $\mathrm{S}$ approaches the goal box and that the increase in rate is a negatively accelerated function of the amount of training, consistent with the predictions made by Spence (1951). Whereas previous studies have interpreted their results with an inferred $\mathrm{rg}_{\mathrm{g}} \mathrm{s}_{\mathrm{g}}$ mechanism (e.g., Wike \& Barrientos, 1957), the present technique of directly recording anticipatory goal responses in the runway situation provides an operational reference for this mechanism. The adequacy of this reference remains to be tested.

\section{References}

HULL, C. L. Goal attraction and directing ideas conceived as habit phenomena. Psychol. Rev., 1931, 38, 487-506.

SPENCE, K. W. Theoretical interpretations of learning. In C. P. Stone (Ed.), Comparative ps y c hology. (3rd ed.) New York: Prentice-Hall, 1951.

SPENCE, K. W. Behavior theory and conditioning. New Haven: Yale University Press, 1956.

WIKE, E. L., \& BARRIENTOS, G. Selective learning as a function of differential consummatory activity. Psychol. Rep., 1957, 3, 255-258.

\section{Note}

1. The authors would like to thank Dr. Kenneth W. Spence for his advice and critical reading of this paper.

\begin{abstract}
ENGEN, T., \& LIPSITT, L. P. (Brown U.). Decrement and recovery of responses to olfactory stimuli in the human neonate. J. comp. physiol. Ps ychol., in press-Changes in neonates' breathing responses to inert mixtures of anise oil and asafoetida, or amyl acetate and heptanal, are presented. After decrement of this response to the mixture over trials, recovery of the response was obtained with a component of the
\end{abstract}

mixture (e.g., either amyl acetate or heptanal), depending primarily on how psychologically similar the component was to the mixture. The decrement to the mixture is therefore interpreted as evidence for habituation rather than sensory fatigue, and the response to the component appears to be a novelty effect following habituation to the mixture. (Pre-publication copies available from the authors.) 